\title{
Is this clinical trial fully registered? A statement from the International Committee of Medical Journal Editors
}

\author{
Catherine D. De Angelis, Jeffrey M. Drazen, Frank A. Frizelle, Charlotte Haug, John Hoey, \\ Richard Horton, Sheldon Kotzin, Christine Laine, Ana Marušić, A. John P.M. Overbeke, \\ Torben V. Schroeder, Harold C. Sox, Martin B. Van Der Weyden
}

Published at www.cmaj.ca on May 23, 2005.

$\mathrm{I}$ n September 2004, the members of the International Committee of Medical Journal Editors (ICMJE) published a joint editorial aimed at promoting registration of all clinical trials. ${ }^{1}$ We stated that we will consider a trial for publication only if it has been registered before the enrolment of the first patient. This policy applies to trials that start recruiting on or after July 1, 2005. Because many ongoing trials were not registered at inception, we will consider for publication ongoing trials that are registered before Sept. 13, 2005. Our goal then and now is to foster a comprehensive, publicly available database of clinical trials. A complete registry of trials would be a fitting way to thank the thousands of participants who have placed themselves at risk by volunteering for clinical trials. They deserve to know that the information that accrues from their altruism is part of the public record, where it is available to guide decisions about patient care, and deserve to know that decisions about their care rest on all of the evidence, not just the trials that authors decide to report and that journal editors decide to publish.

We are not alone in pursuing this goal. The World Health Organization (WHO), through meetings in New York, Mexico City and Geneva, has brought us close to the goal of a single worldwide standard for the information that trial authors must disclose. Around the world, governments are beginning to legislate mandatory disclosure of all trials. For example, among the bodies considering new legislation is the US Congress, where the proposed Fair Access to Clinical Trials (FACT) Act would expand the current mandate for registration of clinical trials. Many other journals have adopted our policy of requiring trial registration. These initiatives show that trial registration has become a public issue. But, as our deadline for registration approaches, trial authors and sponsors want to be sure that they understand our requirements, so that reports of their research will be eligible for editorial review. The purpose

A French translation of this article is available at www.cmaj.ca/cgi/content/full/172/13/1700/DC1 of this joint and simultaneously published editorial is to answer questions about the ICMJE initiative and to bring our position into harmony with that of others who are working toward the same end.

Our definition of a clinical trial remains essentially the same as in our September 2004 editorial: "Any research project that prospectively assigns human subjects to intervention and comparison groups to study the cause-andeffect relationship between a medical intervention and a health outcome." By "medical intervention" we mean any intervention used to modify a health outcome. This definition includes drugs, surgical procedures, devices, behavioural treatments, process-of-care changes and the like. We update our 2004 editorial to state that a trial must have at least one prospectively assigned concurrent control or comparison group in order to trigger the requirement for registration.

Among the trials that meet this definition, which need to be registered? The ICMJE wants to ensure public access to all "clinically directive" trials - trials that test a clinical hypothesis about health outcomes (e.g., "Is drug X as effective as drug $\mathrm{Y}$ in treating heart failure?"). We have excluded trials from our registration requirement if their primary goal is to assess major unknown toxicity or to determine pharmacokinetics (phase 1 trials). In contrast, we think the public deserves to know about trials that could shape the body of evidence about clinical effectiveness or adverse effects. Therefore, we require registration of all trials whose primary purpose is to affect clinical practice (phase 3 trials). Between these 2 extremes are some clinical trials whose prespecified goal is to investigate the biology of disease or to provide preliminary data that may lead to larger, clinically directive trials.

We recognize that requiring public registration of trials whose prespecified goal is to investigate the biology of disease or to direct further research might slow the forces that drive innovation. Therefore, each journal editor will decide on a case-by-case basis about reviewing unregistered trials in this category. Authors whose trial is unregistered will have to convince the editor that they had a sound rationale when they decided not to register their trial. The ICMJE 
will maintain this policy for the next 2 years. We will then review our experience.

Our September 2004 editorial specified the information that we would require for trial registration. Attendees at a recent meeting of the $\mathrm{WHO}$ registration advisory group identified a minimal registration data set of 20 items (Table 1). The WHO-mandated items collectively address every key requirement that we established in our September 2004 editorial. The ICMJE supports the WHO minimal data set and has adopted it as the ICMJE's requirement: we will consider a trial for publication if the authors register it at inception by completing all 20 fields in the WHO minimal data set. As individual editors, we will review the data in the registration fields when we decide whether to consider the trial for publication. We will consider a registration data set inadequate if it has missing fields or fields that contain uninformative terminology. If an investigator has already registered a clinical trial in a publicly owned, publicly accessible registry using the data fields that we specified in our 2004 editorial, we will consider that registration to be complete as long as each field contains useful information.

Acceptable completion of data fields is an important concern. It shouldn't be, but it is. Many entries in the publicly accessible clinicaltrials.gov database do not provide meaningful information in some key data fields. A search conducted on May 4, 2005 (Deborah Zarin, MD, personal communication) indicates that certain pharmaceuticalcompany entries list a meaningless phrase (e.g., "investiga-

\section{Table 1: Minimal registration data set*}

\begin{tabular}{|c|c|c|}
\hline Item & & Comment \\
\hline & Unique trial number & $\begin{array}{l}\text { The unique trial number will be established by the primary registering entity (the } \\
\text { registry). }\end{array}$ \\
\hline & Trial registration date & The date of registration will be established by the primary registering entity. \\
\hline & Secondary IDs & May be assigned by sponsors or other interested parties (there may be none). \\
\hline & Funding source(s) & Name of the organization(s) that provided funding for the study. \\
\hline & Primary sponsor & The main entity responsible for performing the research. \\
\hline & Secondary sponsor(s) & The secondary entities, if any, responsible for performing the research. \\
\hline & $\begin{array}{l}\text { Responsible contact } \\
\text { person }\end{array}$ & Public contact person for the trial, for patients interested in participating. \\
\hline 8. & Research contact person & Person to contact for scientific inquiries about the trial. \\
\hline & Title of the study & Brief title chosen by the research group (can be omitted if the researchers wish). \\
\hline 10. & $\begin{array}{l}\text { Official scientific title } \\
\text { of the study }\end{array}$ & $\begin{array}{l}\text { This title must include the name of the intervention, the condition being studied } \\
\text { and the outcome (e.g., The International Study of Digoxin and Death from } \\
\text { Congestive Heart Failure). }\end{array}$ \\
\hline 11. & Research ethics review & $\begin{array}{l}\text { Has the study at the time of registration received appropriate ethics committee } \\
\text { approval (yes/no)? (It is assumed that all registered trials will be approved by an } \\
\text { ethics board before commencing.) }\end{array}$ \\
\hline 12. & Condition & $\begin{array}{l}\text { The medical condition being studied (e.g., asthma, myocardial infarction, } \\
\text { depression). }\end{array}$ \\
\hline 13. & Intervention(s) & $\begin{array}{l}\text { A description of the study and comparison/control intervention(s). (For a drug or } \\
\text { other product registered for public sale anywhere in the world, this is the generic } \\
\text { name; for an unregistered drug, the generic name or company serial number is } \\
\text { acceptable.) The duration of the intervention(s) must be specified. }\end{array}$ \\
\hline & $\begin{array}{l}\text { Key inclusion and } \\
\text { exclusion criteria }\end{array}$ & Key patient characteristics that determine eligibility for participation in the study. \\
\hline & Study type & $\begin{array}{l}\text { Database should provide drop-down lists for selection. This would include choices } \\
\text { for randomized versus nonrandomized, type of masking (e.g., double-blind, single- } \\
\text { blind), type of controls (e.g., placebo, active) and group assignment, (e.g., parallel, } \\
\text { crossover, factorial). }\end{array}$ \\
\hline & $\begin{array}{l}\text { Anticipated trial start } \\
\text { date }\end{array}$ & Estimated enrolment date of the first participant. \\
\hline & Target sample size & $\begin{array}{l}\text { The total number of subjects the investigators plan to enrol before closing the trial } \\
\text { to new participants. }\end{array}$ \\
\hline & Recruitment status & Is this information available (yes/no)? (If yes, link to information.) \\
\hline & Primary outcome & $\begin{array}{l}\text { The primary outcome that the study was designed to evaluate. Description should } \\
\text { include the time at which the outcome is measured (e.g., blood pressure at } \\
12 \text { months). }\end{array}$ \\
\hline & $\begin{array}{l}\text { Key secondary } \\
\text { outcomes }\end{array}$ & $\begin{array}{l}\text { The secondary outcomes specified in the protocol. Description should include time } \\
\text { of measurement (e.g., creatinine clearance at } 6 \text { months). }\end{array}$ \\
\hline
\end{tabular}

*The data fields were specified at a meeting convened by the World Health Organization in April 2004; the explanatory comments are largely from the International Committee of Medical Journal Editors. 
tional drug") in place of the actual name of the drug, even though a US law requires trial registrants to provide "intervention name" (www.fda.gov/cder/guidance/4856fnl.htm). Many companies and other entities are completing the data fields in a meaningful fashion. Data entries must include information that will be of value to patients and health professionals; the intervention name is needed if one is to search on that intervention.

We recognize that clinical trial registries have many uses, but, whatever the use, a worldwide uniform standard for a minimal database is necessary. We have participated in the WHO effort to establish a clinically meaningful trial registration process. The ICMJE supports this ongoing project. When it is complete we will evaluate the process and, if it meets our primary objectives, we will adopt it.

We stated our requirements for an acceptable trial registry in the September 2004 editorial, and they remain the same. The registry must be electronically searchable and accessible to the public at no charge. It must be open to all registrants and not for profit. It must have a mechanism to ensure the validity of the registration data.

The purpose of a clinical trials registry is to promote the public good by ensuring that everyone can find key information about every clinical trial whose principal aim is to shape medical decision-making. We will do what we can to help reach this goal. We urge all parties to register new and ongoing clinical trials. If in doubt about whether a trial is "clinically directive," register it. Don't use meaningless phrases to describe key information. Every trial participant and every investigator should be asking, "Is this clinical trial fully registered?"

All authors are members of the International Committee of Medical Journal Editors. Catherine D. De Angelis, Editor-in-Chief, fAMA; Jeffrey M. Drazen, Editorin-Chief, New England Fournal of Medicine; Frank A. Frizelle, Editor, The New Zealand Medical Fournal; Charlotte Haug, Editor-in-Chief, Norwegian Medical fournal; John Hoey, Editor, CMA7; Richard Horton, Editor, The Lancet; Sheldon Kotzin, Executive Editor, MEDLINE, National Library of Medicine; Christine Laine, Senior Deputy Editor, Annals of Internal Medicine; Ana Marušić, Editor, Croatian Medical fournal; A. John P.M. Overbeke, Executive Editor, Nederlands Tijdschrift voor Geneeskunde (Dutch fournal of Medicine); Torben V. Schroeder, Editor, Fournal of the Danish Medical Association; Harold C. Sox, Editor, Annals of Internal Medicine; Martin B. Van Der Weyden, Editor, The Medical Journal of Australia.

\section{Reference}

1. De Angelis C, Drazen JM, Frizelle FA, Haug C, Hoey J, Horton R, et al Clinical trial registration: a statement from the International Committee of Medical Journal Editors [editorial]. CMA7 2004;171(6):606-7.

Correspondence to: Dr. John Hoey, Editor, CMAJ, 1867 Alta Vista Dr., Ottawa ON K1G 3Y6; fax 613 565-5471;

john.hoey@cma.ca
THE FRAMEWORK for HIGH STANDARDS and DEDICATION

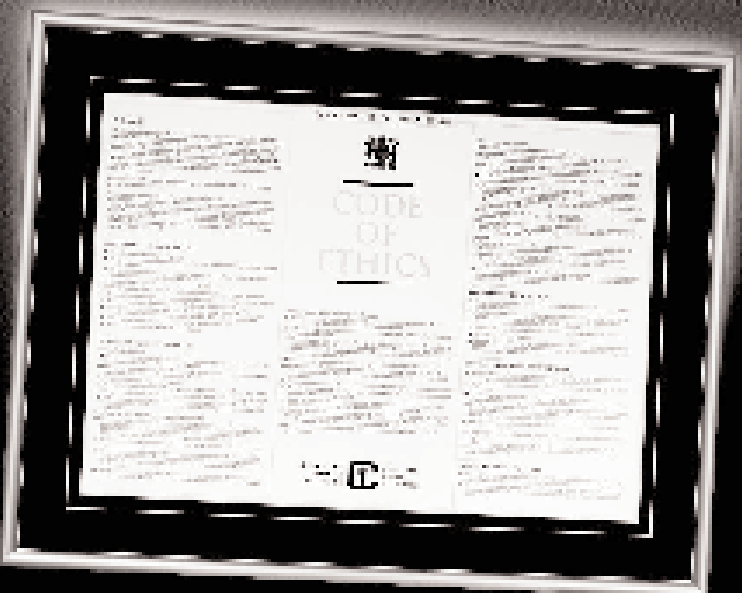

Patients rby an you for your expertive, ompesionand integiby.

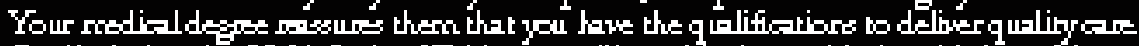
Bydieforire the CMLA Code of Ethiss you will provide them with the added corfideres that ycu hove the hish sandads and dedizetion bo alway wodk in their test interes.

The most sosent verion of the Code of Erive (Alloust 200 ) is now arihble ina poliched

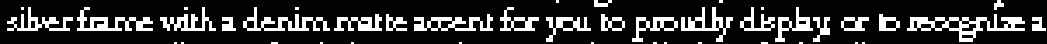

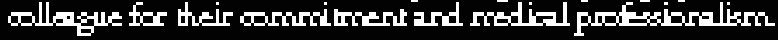

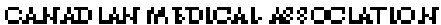

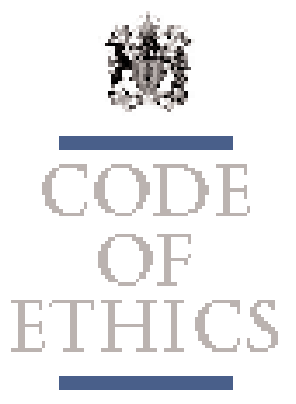

Yougn p be pour onder by vele phore throush the Crive Member Service Centre at $1888855-2555$

oronline 가 cma_ca' craboolshthr. Online odecinsis a rubble to vecisted uess of cman vecistration is fiee to Caradian physicins and onty alss 2 minut.

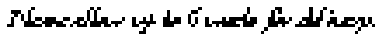

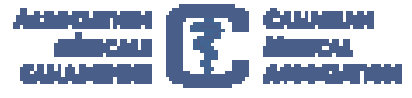

